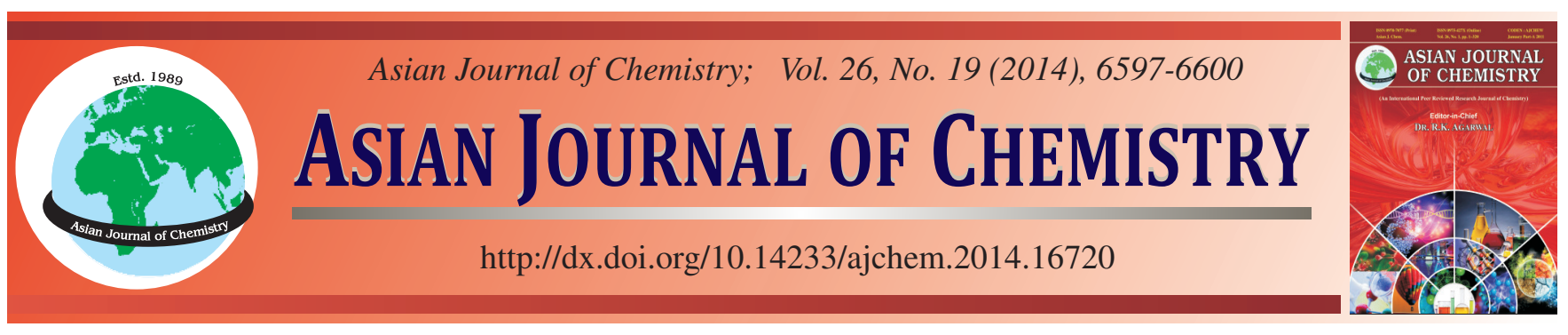

\title{
Influence of Different Factors on the Removal of Ammonia by Electrolysis with Three-Dimensional Electrode
}

\author{
Liang Li, Cuinong Song, Yuanxing Huang ${ }^{*}$ and Yuemei Zhou
}

School of Environment and Architecture, University of Shanghai for Science and Technology, No. 516 Jungong Road, Shanghai 200093, P.R. China

*Corresponding author: Fax: +86 21 55271722; Tel: +86 21 55271501; E-mail: yuanxinghuang@ 126.com

\begin{abstract}
Electrolytic removal of ammonia was investigated by using zeolite packed three dimensional electrode reactor under batch mode. The results showed that 6-100 mg N/L ammonia could be successfully removed within $1-7 \mathrm{~h}$ under various conditions of $30-300 \mathrm{mg} / \mathrm{L}$ chloride ion concentration, 0.5-2 A current and $\mathrm{pH} 3-9$. Current density and initial ammonia concentration had significant effect on the ammonia removal rate, while the influence of chloride concentration and $\mathrm{pH}$ was weak under batch mode in this research. For the treatment of municipal sewage, the ammonia concentration was reduced from $27.8 \mathrm{mg} \mathrm{N} / \mathrm{L}$ to $0.5 \mathrm{mg} \mathrm{N} / \mathrm{L}$ after $1.5 \mathrm{~h}$ electrolysis. Moreover, 72 and $61 \%$ removal of the total nitrogen and COD could be achieved after continue electrolysis for $2.25 \mathrm{~h}$.
\end{abstract}

Keywords: Three-dimensional electrode, Electrochemical oxidation, Ammonia, Zeolite.

\section{INTRODUCTION}

Nowadays eutrophication is one of most serious environmental problems in China. In general, excess discharge of nutritious elements such as nitrogen and phosphorus are recognized as the main reason for algae blooming. In wastewater, ammonia is one of the most important forms of nitrogen contamination due to its characteristics of oxygen consumption, promotion to algae growth, toxicity to fish etc. Low limits of 0.02 and $0.1 \mathrm{mg} / \mathrm{L}$ of unionized ammonia $\left(\mathrm{NH}_{3}\right)$ are suggested for chronic and acute toxicity, respectively ${ }^{1}$. Deep removal of ammonia from the secondary effluent of sewage discharge facility has become a challenge issue.

As one of the advanced oxidation methods, electrochemical oxidation has attracted more and more attention due to its effectiveness, environmental friendly products, easy operation and maintenance. Many researchers have reported that electrochemical process can be used for removal of refractory organics, nitrate, ammonia, heavy metals, etc. ${ }^{2-4}$. For example, significant chemical oxygen demand (COD) and ammonia removal as well as decolourization have been observed by Rao et al. ${ }^{5}$ when treating tannery wastewater with $\mathrm{Ti} / \mathrm{Pt}, \mathrm{Ti} / \mathrm{PbO}_{2}$, and $\mathrm{Ti} / \mathrm{MnO}_{2}$ as anodes and Ti plate as cathode.

The electrolytic removal of contaminants from wastewater was found to be related to various factors such as electrode materials, electrolyte, current, $\mathrm{pH}$, type of reactor, etc $^{6}$. Previous studies have summarized that higher current density and electrolyte concentration, neutral $\mathrm{pH}$ condition could promote the reaction rate of ammonia. In addition, the electrode materials were the most important factor for the ammonia removal rate. As the electrode materials changed, the ammonia removal rate altered. Moreover, ammonia was proved to have obvious effects on the phenol removal efficiency in chloride mediated system during electrochemical oxidation with $\mathrm{RuO}_{2}-\mathrm{Pt} / \mathrm{Ti}$ as anode and Ti plate as cathode ${ }^{7}$. In recent years, 3D electrode reactors had been successfully applied to the treatment of landfill leachate, tannery wastewater, textile wastewater etc $^{8-10}$, which was proved to significantly enhance the mass transfers as well as contaminants removal.

In this research, 3D electrode reactor was designed for deep and fast removal of ammonia by electrolysis. Different influencing parameters including current, chloride ion concentration, $\mathrm{pH}$ and initial ammonia concentration were investigated for electrocatalytic ammonia removal by using bipolar 3D electrode reactor. Typical secondary effluent from sewage discharge facility was treated to evaluate the application of the system in real situation.

\begin{tabular}{l} 
EXPERIMENTAL \\
\hline$\left(\mathrm{NH}_{4}\right)_{2} \mathrm{SO}_{4}, \mathrm{NaCl}, \mathrm{Na}_{2} \mathrm{SO}_{4}, \mathrm{H}_{3} \mathrm{BO}_{3}, \mathrm{H}_{2} \mathrm{SO}_{4}$ and $\mathrm{NaOH}$ were \\
all of analytical grade purchased from Sinopharm Chemical \\
Reagent Co., Ltd (Shanghai, China). Distilled water was used \\
as the solvent to prepare synthetic wastewater with ammonia \\
$\left(\mathrm{NH}_{3}+\mathrm{NH}_{4}^{+}\right)$, chloride ion $\left(\mathrm{Cl}^{-}\right)$and suitable electro conduc- \\
tivity. The final pH of the synthetic solution was adjusted \\
by using $\mathrm{H}_{2} \mathrm{SO}_{4}$ and $\mathrm{NaOH}$ with the help of a pH meter. $30 \%$
\end{tabular}


solution of boric acid was prepared as adsorption solution for ammonia eluting.

Set-up and procedure: Batch electrolysis system was employed to investigate the influence of different factors on electrolytic removal of ammonia by three dimensional electrode. The experimental set-up was composed of DC power supply, circulating pump, gas washer and collection bag and $3 \mathrm{D}$ electrode reactor with $\mathrm{RuO}_{2} / \mathrm{Ti}$ anode, stainless steel cathode and 2-3 mm natural zeolite particle electrode. The wastewater containing ammonia was passed through the $3 \mathrm{D}$ electrode reactor with the force of the pump at a constant flow rate of $150 \mathrm{~mL} / \mathrm{min}$. During electrolysis, samples were taken and analyzed immediately, and the eluting ammonia in the gases was adsorbed in the gas washer and analyzed after the experiment.

Electrolytic experiments: Batch mode was employed to evaluate the electrolytic removal efficiency of ammonia by bipolar 3D electrode. The possible influencing factors were investigated by using simulated domestic sewage. Single factor approach was used to test the effect of initial ammonia concentration, current density, chloride concentration and $\mathrm{pH}$. Each time, only one experiment factor was changed while other factors were kept same as shown in Table-1. Actual wastewater from Dongqu wastewater treatment plant was taken to evaluate the efficiency of electrolytic ammonia removal in real situation.

\begin{tabular}{cccc}
\multicolumn{4}{c}{ TABLE-1 } \\
\multicolumn{4}{c}{ SINGLE FACTOR EXPERIMENTAL CONDITION } \\
\hline $\mathrm{C}_{\mathrm{NH}_{3}-\mathrm{N}}(\mathrm{mg} / \mathrm{L})$ & $\begin{array}{c}\text { Current density } \\
\left(\mathrm{mA} / \mathrm{cm}^{2}\right)\end{array}$ & $\mathrm{C}_{\mathrm{Cl}}(\mathrm{mg} / \mathrm{L})$ & $\mathrm{pH}$ \\
\hline $10,30,50,100$ & 13.7 & 300 & 7 \\
30 & $3.8,7.6,11.4,13.7$ & 300 & 7 \\
30 & 13.7 & $30,120,225,300$ & 7 \\
30 & 13.7 & 300 & $3,7,9$ \\
\hline
\end{tabular}

Detection method: Ammonia was measured according to standard methods ${ }^{11}$. COD was determined by low range COD reagent (HACH, Loveland, Colo.). $\mathrm{pH}$ was measured by a pH meter (PHS-2C, Leici Company, Shanghai, China). Total nitrogen was measured by a TOC/TN analyzer (Multi N/C 3100, Analytikjena Company, Germany).

\section{RESULTS AND DISCUSSION}

After each experiment, the concentration of ammonia in gas washer was measured and the result showed that ammonia volatilization was less than $1 \%$. So the amount of ammonia removed through volatilization can be ignored.

Current density: In order to investigate the effects of ammonia removal by zeolite through ion-exchange and adsorption, synthetic wastewater containing $29.5 \mathrm{mg}$ N/L ammonia and $300 \mathrm{mg} / \mathrm{L}$ chloride was circulated inside the experimental setup. The change of ammonia was shown in Fig. 1, which indicated that in the beginning $15 \mathrm{~min}$ rapid adsorption resulted in $50 \%$ removal of ammonia. Slow adsorption of ammonia was observed in the following $3 \mathrm{~h}$ and the final ammonia concentration was measured to be $6.8 \mathrm{mg} \mathrm{N} / \mathrm{L}$. To evaluate the effect of current densities, the same synthetic wastewater were electrolyzed under the currents of $0.5 \mathrm{~A}, 1.0 \mathrm{~A}, 1.5 \mathrm{~A}$ and 1.8 A, respectively. As shown in Fig. 1, more than $99 \%$ of ammonia could be removed in $3,2,1.5$ and $1.5 \mathrm{~h}$, respectively, while $12,7,4$, and $2.5 \mathrm{~h}$ of electrolytic time were needed to achieve similar results under the same conditions when using traditional 2D electrode in previous research ${ }^{12}$. The efficiency of ammonia removal by $3 \mathrm{D}$ electrode reactor increased significantly as compared with 2D electrode. Moreover, it was obviously that higher contaminant removal rate was obtained when higher current density was applied, which was similar with the results obtained by Rosilda and his co-workers ${ }^{13}$ studied the ammonium ion removal from produced water by a batch single-stage electrolytic process using $\mathrm{RuO}_{2}+\mathrm{TiO}_{2} / \mathrm{Ti}$ as anode and pure titanium plate as cathode. From previous research with $\mathrm{RuO}_{2} / \mathrm{Ti}^{12}$ and $\mathrm{IrO}_{2} / \mathrm{Ti}^{14}$ anode, electrolytic ammonia oxidation followed pseudo-zero order kinetics at different currents. This difference could be attributed to the combination reaction of ion-exchange and electrochemical oxidation in $3 \mathrm{D}$ electrode reactor. Although high ammonia removal rate was observed under high current, energy cost would be significantly increased.



Fig. 1. Effect of current density on the electrolytic removal of ammonia

Chloride ion concentration: Chloride ion concentration in the system was very important for ammonia oxidation because of the formation of $\mathrm{HClO}$ or $\mathrm{ClO}^{-}$. As shown in Fig. 2, the electrolytic removal of ammonia was investigated under different chloride ion concentrations between 30 and $300 \mathrm{mg} / \mathrm{L}$. After $1.5 \mathrm{~h}$ electrolysis, the ammonia concentration decreased from $30 \mathrm{mg}$ N/L to less than $1 \mathrm{mg} \mathrm{N} / \mathrm{L}$ under all chloride concentrations, which was different from the result obtained by $2 \mathrm{D}$ electrode. Vanlangendonck et al. ${ }^{15}$ and Li \& Liu ${ }^{12}$ concluded that high chloride concentration had positive influence on ammonia oxidation rate because higher concentration was beneficial for hypochlorite production. The improved removal in this experiment might due to ammonia adsorption on zeolite and simultaneously electrocatalytic regeneration of zeolite during electrolysis with 3D electrode.

pH: In aqueous solution, the form of ammonia is significantly affected by $\mathrm{pH}^{16}$. Under $\mathrm{pH} 9.25, \mathrm{NH}_{4}{ }^{+}$accounts for $50 \%$ and $\mathrm{NH}_{3}$ takes the other half. Under $\mathrm{pH} 7, \mathrm{NH}_{4}{ }^{+}$rises from 50 $\%$ to 99.4 percent, which was possible to affect the electrolytic removal of ammonia by $3 \mathrm{D}$ electrode. As shown in Fig. 3, electrolytic removal of ammonia were studied under $\mathrm{pH} \mathrm{3,7}$ and 9 , the results showed that the ammonia concentrations 


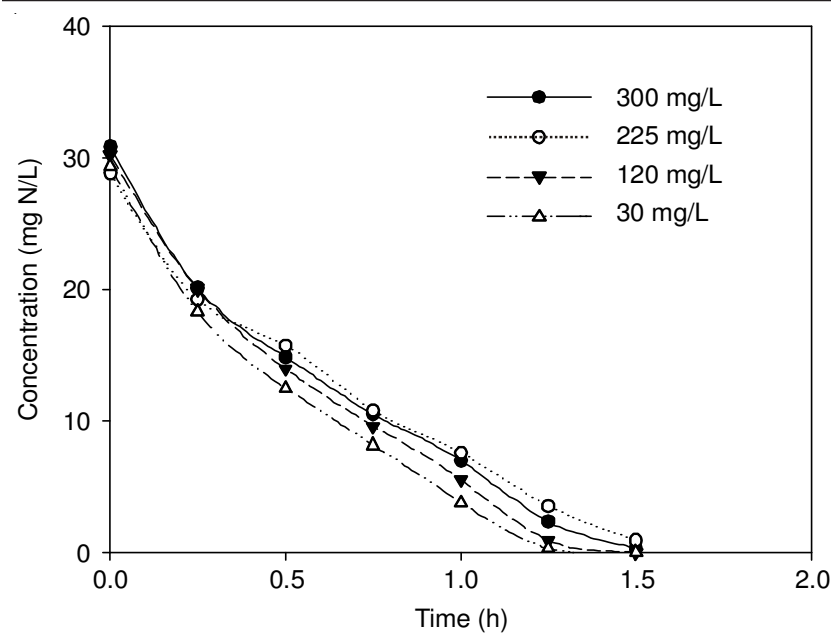

Fig. 2. Effect of chloride ion concentration on the electrolytic removal of ammonia

were $1.5,0.3$ and $0.6 \mathrm{mg} \mathrm{N} / \mathrm{L}$, respectively, after $1.5 \mathrm{~h}$ electrolysis. When $\mathrm{pH}$ was 3 , the removal rate of ammonia was slightly lower than results obtained under $\mathrm{pH} 7$ and 9. This suggested that $\mathrm{pH}$ had little influence on ammonia oxidation so the removal of ammonia by electrochemical oxidation can adapt to relatively wide $\mathrm{pH}$ range. It was consistent with the results obtained by Mahvi et al. ${ }^{17}$ who observed that the contaminant removal efficiency had no obvious difference over the entire range of $\mathrm{pH}$ values from 5 to 10 . Moreover, Vanlangendonck et al..$^{15}$ demonstrated that $\mathrm{pH}$ values between 5.5 and 10 had no effect on ammonia oxidation rate when using stainless steel as cathode and $\mathrm{TiO}_{2}+\mathrm{RuO}_{2} / \mathrm{Ti}$ as anode to treat power plants wastewater.

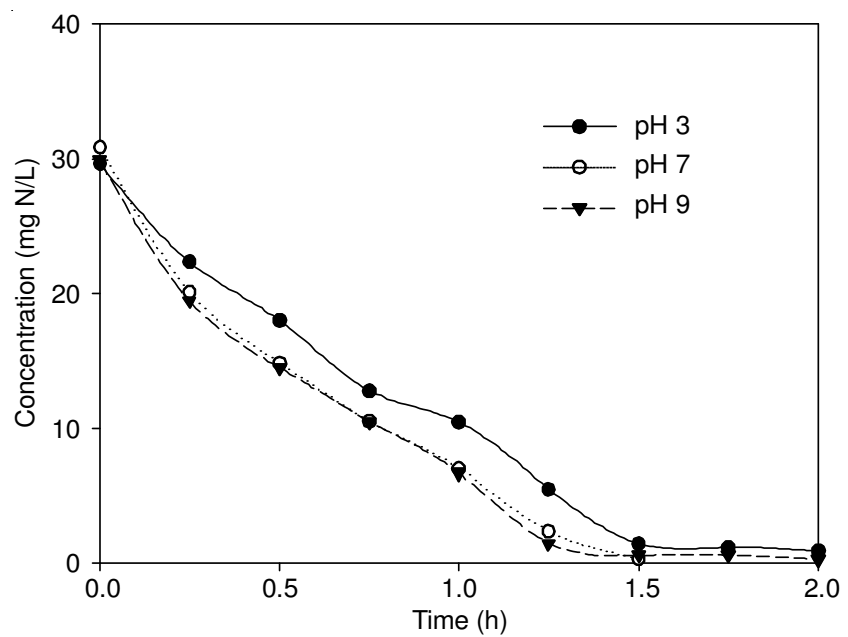

Fig. 3. Effect of $\mathrm{pH}$ on the electrolytic removal of ammonia

Initial ammonia concentration: In actual municipal sewage, the ammonia concentration usually fluctuated around $30 \mathrm{mg} \mathrm{N} / \mathrm{L}$, and possibly increase if it was mixed with agriculture runoff or industrial wastewater. In this research, the performance of 3D electrode was evaluated using synthetic ammonia wastewater with concentrations ranging from 6 to $99 \mathrm{mg}$ N/L. The results showed that either under low or high ammonia concentrations, ammonia could be completely removed given sufficient electrolysis time. As shown in Fig. 4, $0.5,1.5,2.5$ and $6.5 \mathrm{~h}$ of electrolysis time were needed to reach an effluent ammonia concentration lower than $1 \mathrm{mg} \mathrm{N} / \mathrm{L}$ for initial ammonia concentrations of $6,30,50,99 \mathrm{mg} \mathrm{N} / \mathrm{L}$, respectively. Under the same condition, 1, 2.5, 4.5 and $8.5 \mathrm{~h}$ of electrolysis time were needed to achieve the same effect when using traditional 2D electrode reactor ${ }^{12}$. So the ammonia removal rate by $3 \mathrm{D}$ electrode was significantly improved compared with $2 \mathrm{D}$ electrode.

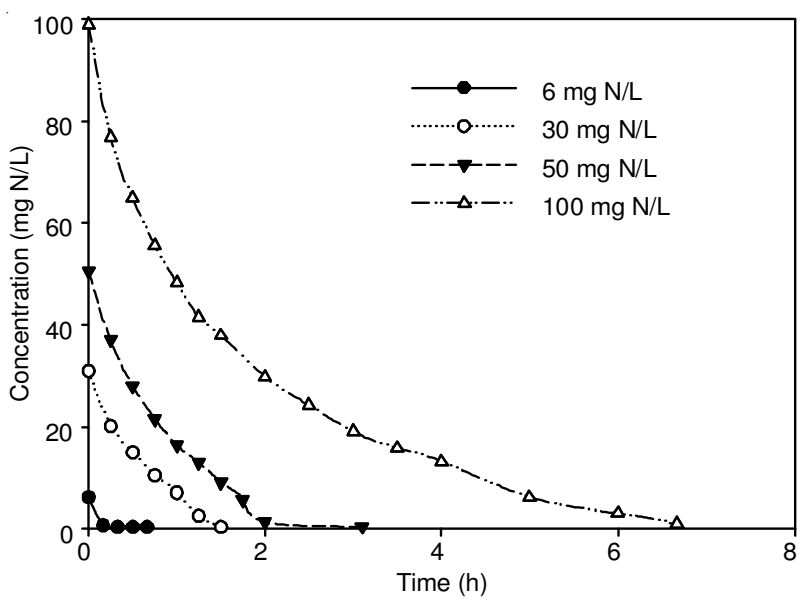

Fig. 4. Effect of initial ammonia concentration on the electrolytic removal of ammonia

Performance of 3D electrode in treating actual municipal sewage: The actual wastewater was taken from Dongqu wastewater treatment plant in Shanghai, which was used to evaluate the efficiency of electrolytic for ammonia removal under the condition of 1.8 A current, $\mathrm{pH} 7$ and $300 \mathrm{mg} / \mathrm{L}$ chloride ion concentration. As shown in Fig. 5, the changes of COD, total nitrogen and ammonia were determined. After electrolysis for $1.5 \mathrm{~h}$, the ammonia concentration decreased from $27.8 \mathrm{mg} \mathrm{N} / \mathrm{L}$ to $0.5 \mathrm{mg} \mathrm{N} / \mathrm{L}$, which met the demand of The First Grade of Environment Quantity Standards for surface water in China. In addition, the total nitrogen concentration decreased from 30.6 to $8.6 \mathrm{mg} \mathrm{N} / \mathrm{L}$ within $2.25 \mathrm{~h}$, which accounted for $72 \%$ ammonia removal from aqueous phase. As for organic compounds, the COD concentration decreased from $38 \mathrm{mg} / \mathrm{L}$ to $15 \mathrm{mg} / \mathrm{L}$ after $2.25 \mathrm{~h}$ electrolysis, which accounted for $61 \%$ removal. These results indicated that bipolar 3D electrode was a promising method for deep and rapid removal of ammonia in domestic sewage.

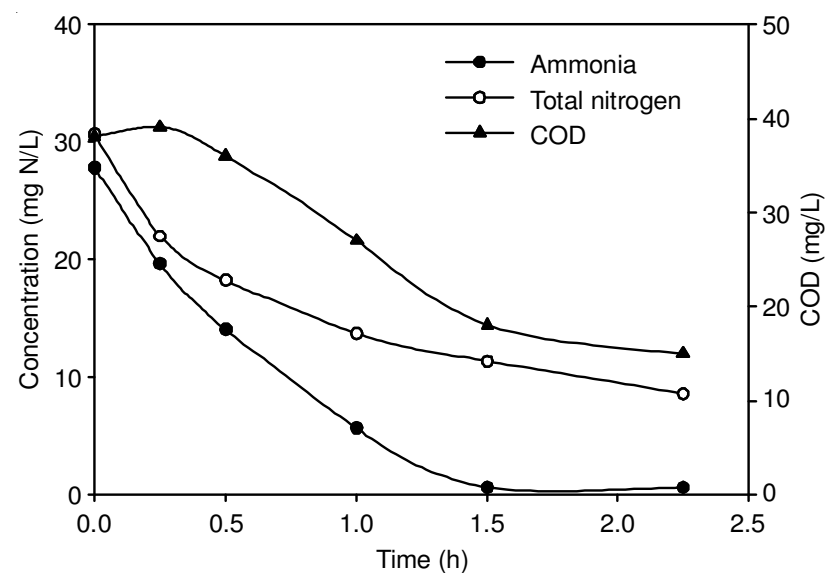

Fig. 5. Ammonia removal in municipal wastewater treated by 3D electrode 


\section{Conclusion}

Enhanced ammonia removal was observed by electrolysis with bipolar 3D electrode reactor with $\mathrm{RuO}_{2} / \mathrm{Ti}$ as anode, stainless steel as cathode and natural zeolite as particle electrode. Under various conditions, faster ammonia removal rates were achieved when compared with traditional 2D electrode reactor. Current density and initial ammonia concentration was found to have significant effect on the ammonia removal rate while the effect of chloride ion concentration and $\mathrm{pH}$ was weak. Moreover, 3D electrode reactor showed good performance for ammonia removal in treating actual municipal sewage. 27.8 $\mathrm{mg} \mathrm{N} / \mathrm{L}$ ammonia could be reduced to $0.5 \mathrm{mg} \mathrm{N} / \mathrm{L}$ within $1.5 \mathrm{~h}$, which met the demand of The First Grade of Environment Quantity Standards for surface water in China.

\section{ACKNOWLEDGEMENTS}

The authors thank the National Natural Science Foundation of China (No. 51208299), Science and Technology Commission of Shanghai Municipality (No. 11JC1408700), and "Chen Guang" project supported by Shanghai Municipal Education Commission and Shanghai Education Development Foundation (No. 11CG52) for funding support.

\section{REFERENCES}

1. V. Amstutz, A. Katsaounis, A. Kapalka, C. Comninellis and K.M. Udert, J. Appl. Electrochem., 42, 787 (2012).

2. X. Ma, R. Wang and W. Guo, Int. J. Electrochem. Sci., 7, 6012 (2012).

3. D. Reyter, D. Belanger and L. Roue, Water Res., 44, 1918 (2010).

4. M. Li, C. Feng, W. Hu, Z. Zhang and N. Sugiura, J. Hazard. Mater., 162, 455 (2009).

5. N.N. Rao, K.M. Somasekhar, S.N. Kaul and L. Szpyrkowicz, J. Chem. Technol. Biotechnol., 76, 1124 (2001).

6. K.-W. Kim, Y.-J. Kim, I.-T. Kim, G.-I. Park and E.-H. Lee, Electrochim. Acta, 50, 4356 (2005).

7. Z. Chao, C.P. Feng and L.Z. Hou, National Key Technology R\&D Program in the 11th Five Year Plan of China (2009).

8. M. Zhou, W. Wang and M. Chi, Bioresour. Technol., 100, 4662 (2009).

9. H. Zhang, Y. Li, X. Wu, Y. Zhang and D. Zhang, Waste Manage., 30, 2096 (2010).

10. A.M. Polcaro, S. Palmas, F. Renoldi and M. Mascia, Electrochim. Acta, 46, 389 (2000).

11. APHA, American Public Health Association, Washington D.C., edn 20 (1998).

12. L. Li and Y. Liu, J. Hazard. Mater., 161, 1010 (2009).

13. R.M.G. de Lima, G.R. da Silva Wildhagen, J.W.S.D. da Cunha and J.C. Afonso, J. Hazard. Mater., 161, 1560 (2009).

14. Y. Liu, L. Li and R. Goel, J. Hazard. Mater., 167, 959 (2009).

15. Y. Vanlangendonck, D. Corbisier and A. Van Lierde, Water Res., 39, 3028 (2005).

16. P.B. Moraes and R. Bertazzoli, Chemosphere, 58, 41 (2005).

17. A.H. Mahvi, S.J.A.- Ebrahimi, A. Mesdaghinia, H. Gharibi and M.H. Sowlat, J. Hazard. Mater., 192, 1267 (2011). 